\title{
Conferences/Seminars
}

\section{Second International Islamic Conference on Prevention of Drugs and Alcohol Islamabad, Pakistan}

Shawwäl 26-28 1409/June 1-3, 1989

More than four hundred scholars and guests from around the world attended the "Second International Islamic Conference on Prevention of Drugs and Alcohol" held at the International Islamic University, Islamabad, Pakistan Shawwäl 26-28 1409/June 1-3, 1989.

The conference, sponsored by Rabita al-Alam al-Islami, Makkah alMukarramah (World Muslim League), and the IIU in Islamabad, re-affirmed the commitment of the Muslim Ummah to eliminate the threat and menace of drugs and alcohol in Islamic states and societies world-wide.

Scholars attending the conference represented both the natural and social sciences, and individual professions ranged from medical doctors and law enforcement authorities to social engineers and Islamic authorities in Seerah and Shariah. More than 70 scholars presented papers on critical aspects of the problem. The conference agenda embraced six major concerns:

1) The Nature and Extent of Drug Abuse.

2) Biological Mechanism.

3 ) Religious and Educational Outlook.

4) Social Context of Drug Abuse. 


\section{5) Community and Drug Control, and}

6) Control of Supply and Demand.

Among the papers presented, several were significant. M. Taha Qureshi's paper, Modalities for Drug Abuse Prevention: Pakistan's Experience, that chronicled the emergence of heroin in Pakistan, highlighted the first session.

Until 1980, "Pakistan was a heroin-free country," according to Qureshi. He cited as factors for heroin's emergence: the Russian occupation of Afganistan that disturbed the opium trafficking routes to Western countries and caused the re-routing of processed heroin through Pakistan; the use of Pakistan's mainland for opium production; and prohibition (Hadd enforcement) that closed small opium vending shops in Pakistan. He suggested that one of every nineteen male adults "will have a brush with drugs," if the trend in heroin traffic continues.

Isam al-Din Hamid al-Sharbini's paper on the Physiological Harms of Alcohol and Narcotics, stressed the bio-psychological effects of drugs during the second session. Al-Sharbini pointed out that the bio-psychological effects of drugs and alcohol include the degeneration of the nervous system; psychoneurological diseases, including memory and logical-thought impairment; digestive system damage; problems of the heart; psychosis and sexual inadequacy.

In the third session Gamal Abou El Azayem presented a paper on the Role of the Mosque in Confronting the Epidemic of Substance Abuse followed by Haji Jummat Bin Dato Muhammad Noor's paper on Schools and Agencies for Preventive Drug Education: The Malaysian Experience.

Azayem's paper was based on experiments conducted in Egypt using mosques as centers for prevention and treatment. These experiments involved efforts to enlist Imams and mosque facilities in therapeutic training systems which included basic Islamic rituals such as prayer (salah) as part of treatment efforts. Noor's paper detailed Malaysia's state-wide effort that began in 1983 with drugs being declared a "national security threat." He presented data on efforts which included integrated school-based community oriented programs; youth camps; curriculum planning, and treatment and prevention programs.

In the fourth session, Ghayth Nur Kashif, one of two Muslim-Americans attending the conference, emphasized the social context of drug abuse and presented a case-study of the positive efforts Muslim-Americans are making in combating the menace of drugs in the U.S.

In his paper entitled, The Menace of Drug Abuse: Protecting Society and its Youth, Kashif noted that there are " 23 million users of illicit drugs in the U.S." He presented researched data on the cost and damage of drug abuse upon the social fabric of society and trends in detection and prevention methods. In outlining the Muslim-American success, he presented a seven- 
pronged approach which included Islamic dawah (propagation), psychological and eco-social survival skills, youth oriented activities, parental involvement, effective utilization of the media, and positive cultural appreciation.

The fifth session heard Hassabo Suliman's presentation on Alcohol and Family Impairment. He presented the results of a survey of 68 alcoholics and their families in Sudan. He noted that "All the family members suffered ill-effects where alcoholism existed within the family unit. These effects included such things as morbid depression, suicidal tendencies, anxieties, etc." The attending problems of loss of homes and jobs, followed by separation and divorce and possibly crime, psychosis, etc., were also discussed.

Maj. Gen. Ahmad Ameen al-Hadiqah's paper on Developing a Strategy of International Cooperation in the Struggle Against Narcotics was the high point of the final session. Al-Hadiqah dealt with international strategies in combating narcotic trafficking. He reviewed the present international conventions and varied bi-lateral agreements between affected states. He urged the closing of obvious existing loopholes in present interdiction methods.

From the viewpoint of the participants, the conference was an unqualified success. The following recommendations were presented at the conclusion of the conference:

1. Re-emphasizing Islamic values and culture.

2. Working cooperatively to establish a unified strategy among Islamic states in combating the menace of drugs and alcohol.

3. Making extensive use of the media in the war on drugs and alcohol.

4. Urging all national states to rigidly observe current international convention rules against narcotics trafficking, etc., and to agree upon a world-wide strategy without loopholes.

5. Establishing treatment and prevention facilities as well as outreach programs in the rural areas of affected countries.

6. Securing funding for essential research and the establishment of educational programs and effective curricula for academic institutions.

7. Emphasizing Shariah in law enforcement and judicial decisions. 